\section{Deleterious Effects of Sucrose in Preservative Solutions on Leaves of Cut Roses}

\author{
Albert H. Markhart, III $^{1}$ and Mark S. Harper ${ }^{2}$ \\ Department of Horticultural Science, University of Minnesota, St. Paul, \\ MN 55108 \\ Additional index words. Rosa hybrida, plasmolysis, leaf crisping, water relations, \\ postharvest, water uptake, stomata, abscisic acid
}

\begin{abstract}
Leaves on cut stems of commercially grown Rosa hybrida cv. Kardinal placed in preservative solutions containing sucrose developed necrotic dry patches that began interveinally and progressed toward the major veins until the entire leaf was dehydrated. Ultrastructural observations of initial damage showed disorganized protoplasm and plasmolyzed cells. Leaves on cut stems pretreated with abscisic acid for 24 hours and transferred to preservative solution containing sucrose remained healthy. We propose that sucrose accumulates in the mesophyll cell wall, thus decreasing apoplastic osmotic potential, leading to cell collapse and tissue death.
\end{abstract}

Intensive greenhouse production employing supplemental lighting and $\mathrm{CO}_{2}$ increased cut rose yield (Holley and Goldsberry, 1961; Lavagetto and McNeil, 1964; Mattson and Widmer, 1971). Development of a variety of preservative solutions has extended the vase life and improved quality of cut roses (Marousky, 1971). Preservative solutions, in general, consist of a bactericide, an acidifier, and a carbohydrate, usually sucrose. Sucrose taken up by cut roses increases vase life (Chin and Sacalis, 1977; Sacalis and Chin, 1976) and increases flower size and improves color (Borochov et al., 1976; Durkin, 1979). Although these preservative solutions typically increase postharvest life, several growers have reported a problem with postharvest performance of cut roses grown in closed greenhouses with supplemental lighting and $\mathrm{CO}_{2}$ enrichment. The problem is characterized by rapid leaf deterioration-specifically, interveinal cells lose turgor, collapse, and dehydrate. The symptoms begin between the veins and progress toward the major veins until the entire leaf is pale and crisp. We will refer to this injury as "leaf crisping." Leaf crisping is distinctly different from classical water stress caused by transpiration exceeding absorption, which is usually characterized by loss of leaf turgor, wilting, and tissue death. There is no general loss of leaf turgor and no wilting in leaf crisping. The objective of our research was to determine the cause of leaf crisping, charac-

Received for publication 6 May 1995. Accepted for publication 6 Sept. 1995. Published as paper no. 22,022 of scientific journal series of the Minnesota Experiment Station on research conducted under Minnesota Experiment Station Project 0302-482182. The additional support of Len Busch Roses is gratefully acknowledged. The cost of publishing this paper was defrayed in part by the payment of page charges. Under postal regulations, this paper therefore must be hereby marked advertisement solely to indicate this fact.

${ }^{1}$ Associate Professor.

${ }^{2}$ Graduate Student. terize the damage at the cellular and subcellular level, and recommend solutions to the problem.

Our general approach was to investigate the water relations of cut rose stems under controlled conditions and examine ultrastructural changes in regions of the leaf just beginning to show symptoms. Preliminary experiments demonstrated that cut stems placed in standard preservative solutions rapidly developed crisp leaves, whereas stems placed in tap or distilled water did not. We hypothesized that the preservative solution accumulates in cut rose leaves and leads to the leaf crisping. We also hypothesize that the active crisping agent in the preservative solution is sucrose.

\section{Methods and Materials}

Effect of sucrose concentration. Since our preliminary experiments demonstrated that the absence of sucrose eliminated leaf crisping, we conducted a refined experiment to investigate the dependence of leaf crisping injury on preservative sucrose concentration. Cut rose stems used in this study, unless stated, were Rosa hybrida L.cv. Kardinal grown during the winter (between November and February) in the commercial greenhouses of Len Busch Roses (Plymouth, Minn.). Plants were grown in soil, drip-fertigated as determined by soil tests in $25 \pm 2 \mathrm{C}$ (day)/20 $\pm 2 \mathrm{C}$ (night) greenhouses covered with a double acrylic complete lexalyte. Natural illumination was supplethat provided $200 \mu \mathrm{mol} \cdot \mathrm{m}^{-2} \cdot \mathrm{s}^{-1}$ between 2100 and $0900 \mathrm{HR}$. Carbon dioxide was raised to 800 to $1000 \mu \mathrm{l} \cdot$ liter $^{-1}$ using propane burners. Relative humidity varied from $90 \%$ and $97 \%$ within the canopy throughout the duration of the winter growth period.

Flowering stems were harvested early in the morning, placed immediately in distilled water, and cooled to $5 \mathrm{C}$ until delivery to our laboratory that afternoon. Upon receipt, stem ends were recut under distilled water and almented by high-pressure sodium vapor lights lowed to rehydrate for $2 \mathrm{~h}$ in a $4 \mathrm{C}$ room. After rehydration, stems were retrimmed to $35 \mathrm{~cm}$ and leaves below the second trifoliolate leaf were removed. Experimental material prepared in this way included one rose flower and two leaves, a structure we term a cut rose stem.

Stems were placed in 100-ml graduated cylinders in preservative solutions containing $0.02 \% 8$-hydroxy-quinoline citrate (8-HQC), pH 3.5 (Marousky, 1969), supplemented with $0.25 \%, 0.5 \%, 1.0 \%$, or $2 \%$ sucrose (w/v) and placed in a growth chamber at $25 \pm 1 \mathrm{C}$ under a constant illumination of $170 \mu \mathrm{mol} \cdot \mathrm{m}^{-2} \cdot \mathrm{s}^{-1}$ from fluorescent/incandescent $(75 \% / 25 \%)$ lamps. Relative humidity within the chamber varied from $50 \%$ to $62 \%$ during the course of the experiments. Leaves were visually evaluated for the percentage of a given leaf that was crisped at 24 and $48 \mathrm{~h}$ after beginning treatment.

Effect of abscisic acid. To test the effect of abscisic acid (ABA) on transpiration rate, cut roses were grown and prepared as described above, except that the preservative solutions contained 1) only water, the control without preservatives; 2) only 8-HQC; 3 ) 8-HQC plus $1 \%$ sucrose; and 4) 8-HQC plus ABA. ABA (mixed isomers; Sigma Chemical Co., St. Louis) stock solutions were $10 \mathrm{~mm}$ in ethanol. Aliquots of the ABA stock solution were added to the 8-HQC preservative solution to create the $10-\mu \mathrm{M}$ ABA working solution. An equal amount of ethanol was added to the control solution that did not contain ABA. Water loss from the cut rose stem was determined by periodically measuring solution loss from the graduated cylinder for $92 \mathrm{~h}$. Solution was replaced as needed. Solution loss from graduated cylinders without cut rose stems was negligible. Although we directly measured water uptake into the cut stems, we equate this with water loss from the cut stem and will refer to these measurements as water loss or transpiration. We use this terminology because the cut stems were hydrated before we began an experiment and the lag between transpiration and absorption of a stem without roots is negligible. We tested the effect of ABA on leaf crisping in two ways. Initially, cut stems were treated in the modified preservative solution containing $1 \%$ sucrose and $10 \mu \mathrm{M}$ ABA for the entire duration of the experiment. We subsequently adjusted the treatments to expose the cut stems to a $24 \mathrm{~h}$ pulse of an 8-HQC preservative solution with or without $10 \mu \mathrm{M}$ ABA. Stems were then transferred to an 8-HQC preservative solution containing $1 \%$ sucrose. The percentage of individual leaf surface that crisped was monitored for the next $72 \mathrm{~h}$. Our rationale for this second protocol was to simulate a potential postharvest practice that might be commercially useful.

Transpiration rates of winter- and summer-grown roses. Roses were harvested in August from Len Busch Roses' greenhouses and prepared similarly to the roses evaluated in the winter, as described above. Growth temperatures during the summer were $27 \pm 3 \mathrm{C}$ (day) and $22 \pm 2 \mathrm{C}$ (night); there was no supplemental lighting, and relative humidities averaged $80 \%$ during the day and $90 \%$ at night. 


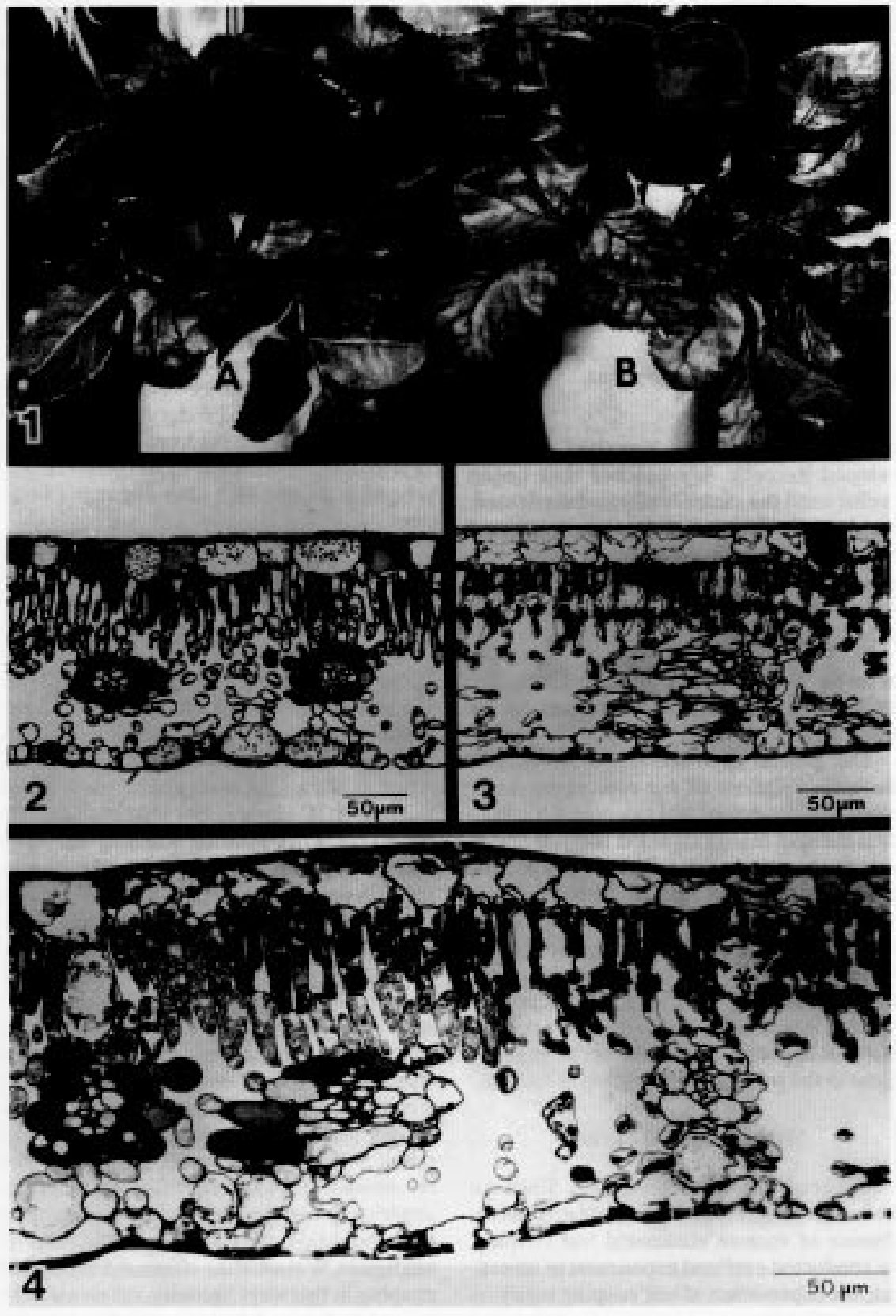

Figs. 1-4. (1) 'Kardinal' cut rose stems placed in (A) 8-HQC and (B) 8-HQC + sucrose. Note the necrotic patches between the secondary veins of the roses treated with sucrose (B). Cross section of (2) healthy rose leaflet; (3) rose leaflet at the initial stages of injury; (4) crisped leaf showing interface between healthy and plasmolyzed cells. The $\left(^{*}\right)$ highlights two plasmolyzed cells.

Transpiration rates were measured for cut rose stems in an 8-HQC (without sucrose) preservative solution as described above.

Experiment design. In all experiments, a single cut and trimmed stem per graduated cylinder was considered an experimental unit. Each treatment was replicated at least 4 times, with cylinders arranged in a completely randomized design within the growth chamber. Experiments were repeated at least twice in time with similar results. Data presented are from one typical experiment. Means and standard errors of the means were calculated and used to compare treatments.

Electron microscopy. To evaluate how the sucrose caused crisping of rose leaf tissue, we vals) followed by pure resin for $1.5 \mathrm{~h}$ (changing at 0.5 -h intervals). Polymerization was carried out in rubber molds for $24 \mathrm{~h}$ at $70 \mathrm{C}$. For light microscopy, 1- $\mu \mathrm{m}$-thick sections of embedded leaf tissue were cut with glass knives and stained with $0.05 \%$ toluidine blue. For transmission electron microscopy, thin sections were cut with a diamond knife on a Reichert ultramicrotome (model OmU2; Vienna, Austria). Sections were collected on uncoated 200-mesh copper grids and stained with $2 \%$ aqueous uranyl acetate followed by a triple-lead stain. Tissue was examined and photographed on a Philips EM300 electron microscope (Mahwah, N.J.) at $60 \mathrm{kV}$.

\section{Results}

Effect of sucrose on leaf crisping. Stems placed in 8-HQC without sucrose did not develop crisped leaves and looked healthy (Fig. 1A). Leaves showed signs of leaf crisping 15 min after stems were placed in the 8-HQC + sucrose solution. Foliar injury was apparent in the form of light-green patches between secondary veins near the basal portion of the leaflet and spread toward the apex. Within 24 $\mathrm{h}$, the yellow patches turned necrotic and became very brittle (Fig. 1B). Sections of leaf tissue not treated with sucrose showed healthy epidermal and mesophyll cells (Fig. 2). Sections through necrotic lesions showed darkstaining palisade and spongy mesophyll cells. Mesophyll cells and adaxial and abaxial epidermal cells possessed much smaller protoplasts than normal (Figs. 3 and 4).

Cells from leaves of cut rose stems in preservative solution without sucrose had no signs of damage (Fig. 5). These cells suffered no structural damage, the membranes were continuous and the organelles were not shrunken or distorted (Figs. 5 and 7). The palisade and spongy mesophyll cells from the sucrose-treated stems were plasmolyzed (Fig. $6)$. The protoplasts of the plasmolyzed cells stained very darkly, probably due to the compressed nature of the cell contents. In Fig. 8, the left cell is plasmolyzed and the chloroplasts are swollen and irregular. Their ultrastructure was so distorted that it was impossible to distinguish the thylakoids from the stroma. Even though the right cell is not plasmolyzed, it is highly disorganized. The internal structures of the chloroplasts, i.e., thylakoids, starch grains, and lipid globules, seemed to float freely within the cytoplasm.

There was a strong relationship between the amount of sucrose in the preservative solution and the amount of damage to leaves. The percentage of crisped leaf tissue increased as sucrose concentration in the preservative solution increased, with leaves of rose stems in $1 \%$ and $2 \%$ sucrose solutions completely crisped after $24 \mathrm{~h}$ (Fig. 9).

The ultrastructural observations and the direct effect of sucrose on leaf damage suggested that sucrose in the preservative solution accumulated in the leaf apoplast. Presumably, the resulting low osmotic potential plasmolyzed the leaf cells and caused cell collapse and tissue death. If this hypothesis is valid, 

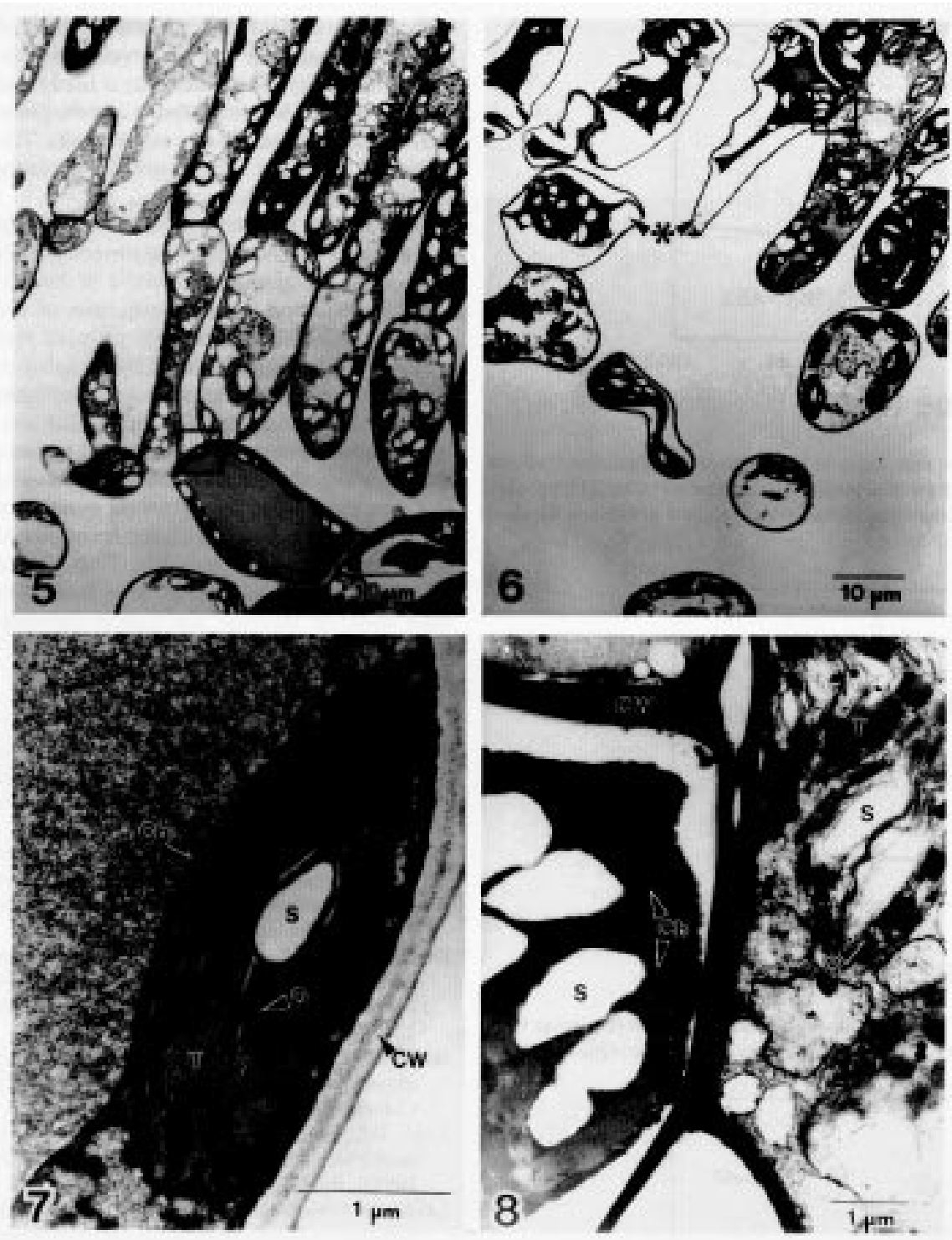

Figs. 5-8. (5) Micrograph of control tissue showing healthy palisade parenchyma cells.(6) Micrograph of sucrose-treated tissue showing plasmolyzed palisade parenchyma cells (*). (7) Enlargement of boxed area in Fig. 5. Control tissue showing cell wall $(\mathrm{CW})$ and a peripheral elongated chloroplast $(\mathrm{Ch})$ containing electron-dense osmophilic lipid globules $(\mathrm{O})$, thylakoids $(\mathrm{T})$, and starch (S). (8) Enlargement of boxed area in Fig. 6. Sucrose-treated tissue showing plasmolyzed palisade parenchyma cells. Note the protoplast containing $\mathrm{Ch}$ and $\mathrm{S}$ of the left cell is pulled away from the $\mathrm{CW}$. Even though the right cell is not plasmolyzed, ultrastructure is altered. Note the free $\mathrm{T}, \mathrm{S}$, and $\mathrm{O}$, which are not contained by chloroplast envelopes.

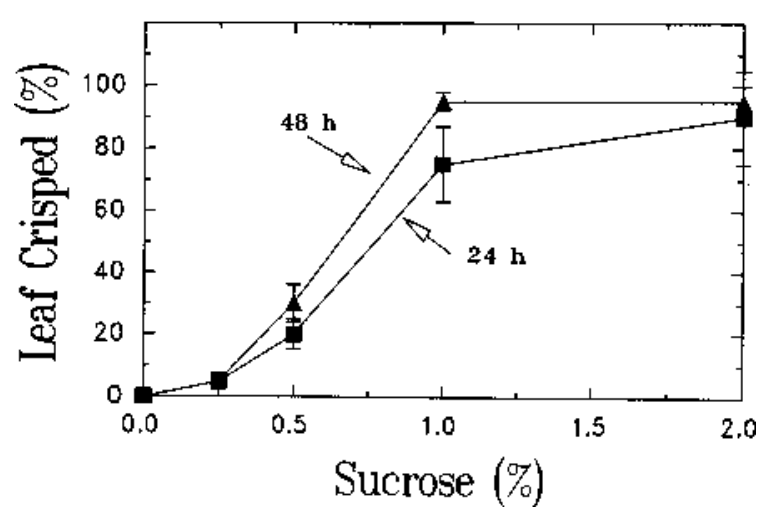

Fig. 9. Effect of sucrose concentration on the percentage of leaf surface crisped either 24 or $48 \mathrm{~h}$ after exposure to HQC preservative solutions with sucrose concentration between $0.25 \%$ and $2 \%$. Means and standard errors are for five replications. then reducing transpiration should reduce leaf crisping. We tested this hypothesis by adding abscisic acid to the preservative solution either as a continuous treatment or as a shortterm pulse.

Continuous ABA treatment had reduced water uptake by $41 \%$ after $96 \mathrm{~h}$ compared to the HQC-treated control cut stems. Cut rose stems held in HQC plus sucrose took up water for several hours, but water uptake rapidly decreased as the sucrose accumulated in the leaves (Fig. 10). ABA pulsing also reduced the rate of water loss (data not presented) and leaf crisping (Fig. 11). Whereas leaves from nonABA-treated stems rapidly crisped, the leaves from ABA-pretreated stems showed very little crisping, with only $\approx 20 \%$ of the leaf surface affected after $72 \mathrm{~h}$.

Winter-grown roses were more susceptible to leaf crisping than summer-grown roses. Summer-grown roses could be forced to crisp by using a preservative solution with $2 \%$ sucrose and exposing the cut stem to a high evaporative demand, i.e., 30C, rapid air movement $\left(5 \mathrm{~m} \cdot \mathrm{s}^{-1}\right)$, and irradiance at 500 $\mu \mathrm{mol} \cdot \mathrm{m}^{-2} \cdot \mathrm{s}^{-1}$ (data not presented).

Water loss from cut stems of summergrown roses was compared with water loss from cut stems of winter-grown roses. Water loss from all cut stems was measured in standard 8-HQC preservative solution without sucrose. The winter-grown roses lost more than twice as much water as the summergrown roses when exposed to similar evaporative demand (Fig. 12).

\section{Discussion}

Our electron micrographs of the initial stages of damage clearly show that plasmolysis and disorganization of the cytoplasm and the organelles were associated with leaf crisping (Figs. 3, 4, and 6). The amount and speed of crisping was related to the amount of sucrose in the preservative solution (Fig. 9). Clearly, sucrose was the cause of the plasmolysis, tissue death, and the crisped leaves in these tests.

Postharvest leaf crisping is most pronounced in rose stems grown in closed greenhouses with supplemental light, elevated $\mathrm{CO}_{2}$, and high relative humidity. These intensive growth conditions produce cut stems that have higher transpiration rates than cut stems from roses grown in summer greenhouses under natural light conditions, no $\mathrm{CO}_{2}$ enrichment, and lower relative humidity (Fig. 12), even when tested under the same conditions. Low resistance to water loss in winter-grown roses and low postharvest humidity would result in high cut rose transpiration rates, which, in turn, would pull large amounts of preservative solution into the leaves. The consequent sucrose accumulation in the apoplast of the leaf would plasmolyze the cells, leading to cell death and leaf crisping.

The reduced transpiration rates induced by adding ABA to the preservative solution (Fig. 10) suggests that the stomata of winter-grown roses are not tightly closed and that forcing stomata closure with ABA reduced leaf crisp- 


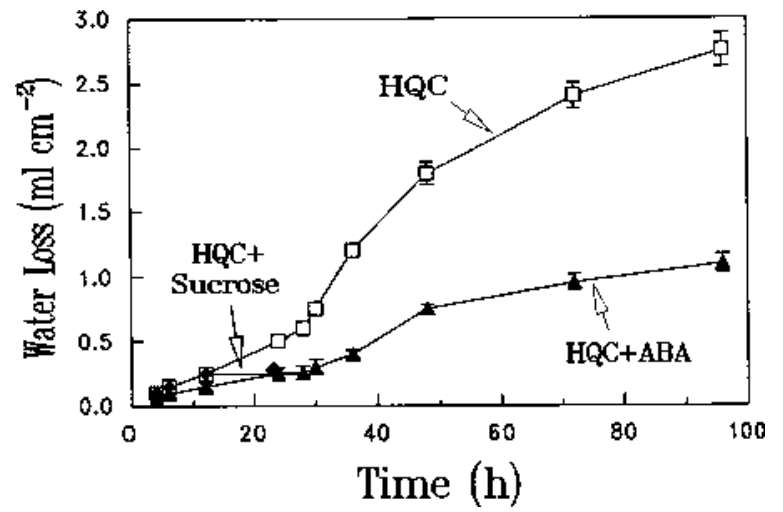

Fig. 10. Effect of ABA on cumulative water loss for cut rose stems in HQC preservative solutions only or also containing $1 \%$ sucrose or $10 \mu \mathrm{M}$ ABA. Data for the treatments with sucrose end after $24 \mathrm{~h}$ because rose stems were completely crisped and not transpiring. Means plus standard errors are for five replications.

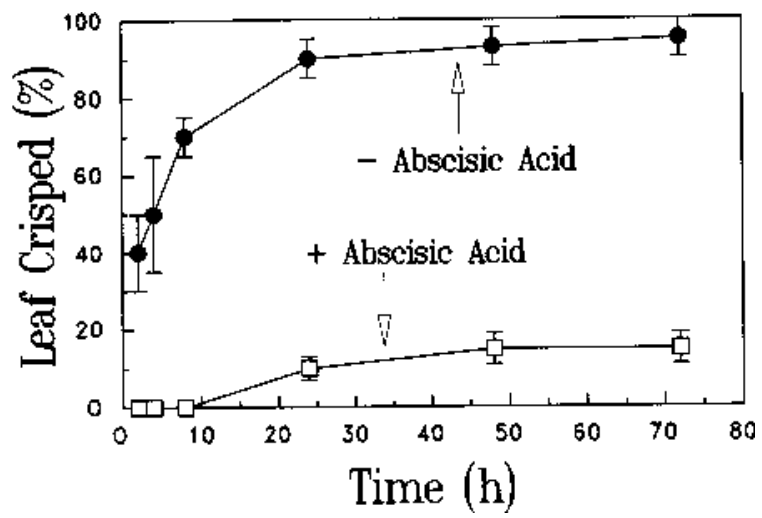

Fig. 11. Effect of a 24-h ABA pulse pretreatment on leaf crisping. Time "zero" is when the stems were transferred to the solution containing sucrose. Means plus standard errors are for five replications.

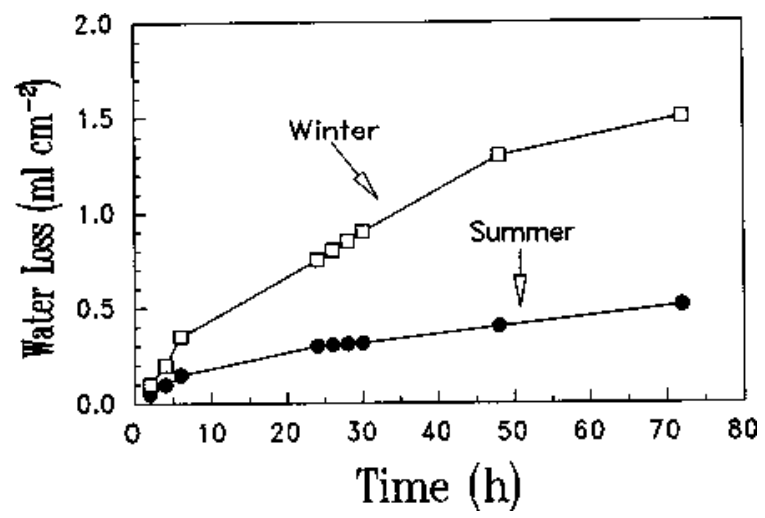

Fig. 12. Cumulative water loss from summer- and winter-grown roses. See methods for details of culture conditions. The standard errors are smaller than the symbols; $\mathrm{n}=5$.

ing. These results are consistent with the findings of Kohl and Rundle (1972) and Borochov et al. (1976), who demonstrated that stomata from roses grown in summer conditions closed in response to $\mathrm{ABA}$. Our results suggest that ABA could be incorporated into the postharvest handling of cut roses to increase the postharvest quality of rose foliage. Contrary to the results of Borochov et al. (1976), we saw no effect of the ABA treatments on bud development or flower longevity. The difference is likely due to the lower $\mathrm{ABA}$ concentration and the pulse ABA treatment used in our experiments. The effect of $\mathrm{ABA}$ on flower quality deserves further investigation.

Our results suggest possible solutions to leaf crisping in roses, the most obvious being to decrease the amount of sucrose in the preservative solution. In our tests, use of the sucrose at $0.25 \%$ significantly reduced leaf crisping and had no effect on flower quality or longevity compared to treatments with higher concentrations. Adding ABA, or an ABA ana$\log$ that causes stomatal closure and reduces transpiration, also may be useful in reducing leaf crisping. Ultimately, growing conditions that produce a leaf with a higher resistance to water loss would be desirable. Thus, future research should address variables that influence stomatal function and cuticle development.

\section{Literature Cited}

Borochov, A., S. Mayak, and A.H. Halevy. 1976. Combined effects of abscisic acid and sucrose on growth and senescence of rose flowers. Physiol. Plant. 36:221-224.

Chin, C. and J.N. Sacalis. 1977. Metabolism of sucrose in cut roses. II. Movement and inversion of sucrose absorbed by cut rose stems. J. Amer. Soc. Hort. Sci. 102:537-540.

Durkin, D.J. 1979. Effect of millipore filtration, citric acid and sucrose on peduncle water potential of cut rose flower. J. Amer. Soc. Hort. Sci. 104:860-863.

Holley, W.D. and K.L. Goldsberry. 1961. Carbon dioxide increases growth of greenhouse roses. Colorado Flower Growers Bul. 139:1.

Kohl, H.C. and D.L. Rundle. 1972. Decreasing water loss of cut roses with abscisic acid. HortScience 73:214.

Lavagetto, F. and A.L. McNeil. 1964. Accelerating winter growth with artificial lighting and carbon dioxide. Florists' Rev. 164:8-11.

Marousky, F.J. 1969. Vascular blockage, water absorption, stomatal opening, and respiration of cut 'Better Time' roses treated with 8hydroxyquinoline citrate and sucrose. J. Amer. Soc. Hort. Sci. 94:223-226

Marousky, F.J. 1971. Inhibition of vascular blockage and increased moisture retention in cut roses induced by $\mathrm{pH}, 8$-hydroxyquinoline citrate, and sucrose. J. Amer. Soc. Hort. Sci. 96:38-41.

Mattson, T.H. and R.E. Widmer. 1971. Year-round effects of carbon dioxide supplemented atmospheres on greenhouse rose (Rosa hybrida) production. J. Amer. Soc. Hort. Sci. 96:487-491.

Sacalis, J.N. and C. Chin. 1976. Metabolism of sucrose in cut roses. I. Comparison of sucrose pulse and continuous sucrose uptake. J. Amer. Soc. Hort. Sci. 101:254-257. 